\title{
A Implementação pela Via Judicial das Políticas Públicas na Área de Saúde Mental: O Papel do Ministério Público
}

\author{
THE JUDICIAL IMPLEMENTATION OF PUBLIC POLICIES IN MENTAL \\ HEALTH: THE ROLE OF THE BRAZILIAN MINISTÉRIO PÚBLICO
}

Pedro Thomé de Arruda Neto ${ }^{\text {(*) }}$

RESUMO

A abordagem da loucura, ao longo da história, não foi linear. Partiu de um momento inaugural, na antiguidade, onde era respeitada e vista como uma emanação da divindade, passando por uma fase de completa intolerância na Europa Medieval e, finalmente, chegando a um modelo desenvolvido nos séculos XVII e XVIII e que passou a vê-la como uma doença a ser tratada, tendo como idealizador o médico francês Philippe Pinel. Trata-se de um paradigma asilar/hospitalar/manicomial/assistencial, em pleno vigor no Brasil, que enxerga o confinamento das pessoas acometidas por transtornos psíquicos como única forma de tratamento da doença mental. Tal postura, foi legalmente superada com a Lei $\mathrm{n}$. 10.216/01, da Reforma Psiquiátrica que passou a enxergar nas pessoas portadoras de sofrimento mental sujeitos de direitos e cidadãos e, assim, humanizou o tratamento mental. Previu a legislação de 2001 uma política específica de desinstitucionalização que foi regulamentada em ato administrativo do Ministério da Saúde, introduzindo no âmbito do SUS as residências terapêuticas. Considerando que o Superior Tribunal de Justiça tem entendimento firmado no sentido de que, dentro de uma visão contemporânea, o Poder Judiciário pode determinar a implementação de políticas públicas, previstas em lei e regulamentadas em ato administrativo, cabe ao Ministério Público, por meio da ação civil pública, a busca da efetivação das mesmas, quando se verificar, na prática, a recalcitrância do Poder Executivo em implementá-las.

Palavras-chave

Saúde Mental; Políticas Públicas; Ministério Público.

(") Promotor de Justiça do Ministério Público do Distrito Federal e Territórios. E-mail: pedrot@mpdft.gov.br. Recebido em 3.10.05. Aprovado em 5.11.05. 


\section{ABSTRACT}

During the History, mental illness has never been dealt with in lineal terms. In antiquity, mental illness was respected and considered an emanation of the Divine; in Medieval Europe it was treated with extreme intolerance in Medieval Europe and finally, during the centuries XVII and XVIII, mental illness was recognized as subject that requests (medical) treatment, a concept idealized by the French physician Philippe Pinel. The treatment of mental illness according to the principle of confinement/hospital treatment/lunatic asylum/medical assistance is still widely practiced in Brazil today, where the confinement of those suffering from mental disturbances is still considered to be the main form of treatment. This practice was legally overturned by the introduction of Law n. 10.216/01, for Psychiatric Reform, and as a result those suffering from mental disturbances began to be viewed as citizens and holders of legal rights and more humane forms of treatment were determined. The Law n. 10.216/01 established a specific policy, regulated by an administrative act approved by the Ministry of Health, to remove patients from mental institutes and introduce them to what is known as "therapeutic (treatment) residences" within the structure of the public Brazilian National Healthy System (SUS). So, from a contemporary viewpoint, the Superior Tribunal de Justiça (High Court) has been judging based on the principle that Judiciary has the right to determine the implementation of public policies, as established by law and implemented by administrative acts, by this way, Public Ministry, by means of a public civil action, has the right to seek the implementation of such laws when the Executive fails to carry them out in practice.

\section{Key words}

Mental Health; Public Policies; Public Ministry (Ministério Público).

\section{LINHAS GERAIS DA EVOLUÇÃO DO PENSAMENTO CIENTÍFICO ACERCA DA SAÚDE MENTAL: DA FALENCIA DO MODELO ASSISTENCIAL À REFORMA PSIQUIÁTRICA}

Abordar a questão da saúde mental não é tarefa simples. O tema se encontra envolto em uma verdadeira "nuvem cinzenta" de preconceitos e tabus de difícil desmanche.

Uma das primeiras constatações a que se pode chegar quando o assunto é saúde mental diz respeito ao fato de que a condição humana do louco é causa de repulsa no seio social. 
As pessoas acometidas por transtornos psíquicos pouca ou nenhuma visibilidade têm em nossa sociedade. Afinal, como diz o ditado popular, "lugar de louco é no hospício".

Entrementes, não há dúvidas de que se faz necessário repensar tal postura e garantir a essa coletividade um tratamento digno e isonômico, nos moldes prescritos pela Lei Maior.

De fato, para que "esconder" ou "encarcerar/confinar" um ser humano que nasceu com uma doença mental ou a desenvolveu durante a vida? Afinal, todo louco representa um risco para a sociedade? Ou será que estaríamos tão-somente diante de cidadãos de segunda classe, inferiores?

São perguntas como essas que nos fazem refletir e chegar a uma conclusão singela: é difícil para o homem médio encarar a doença mental com a serenidade e a sabedoria que ela demanda.

Opta-se, simplesmente, por não enxergar uma realidade que está posta e que a todos nós, enquanto seres humanos, diz respeito. Prefere-se apartar de nossas vistas aquelas pessoas fragilizadas que, sem qualquer culpa, padecem de doenças mentais, segregando-as nos chamados manicômios (hospitais psiquiátricos).

E tudo isso contrariando o bom senso e a constatação de que todos nós poderemos vir a desenvolver um quadro de doença mental (afinal, está cientificamente comprovado que há casos em que se nasce acometido e há outros em que a doença se manifesta ou se desenvolve em idade mais avançada).

Curiosamente, a intolerância nem sempre prevaleceu ao longo da história. Entre os povos antigos (Gregos, Mesopotâmios, Hebreus, Babilônios, Persas e civilizações do Extremo Oriente), por exemplo, a loucura era vista como algo divino e as pessoas acometidas por transtornos psíquicos, como seres iluminados, verdadeiros oráculos.

Nesse sentido registram os professores-pesquisadores da Escola Politécnica de Saúde Joaquim Venâncio da Fundação Oswaldo Cruz (1):

"Na Grécia Antiga, a loucura era considerada uma manifestação divina. O que era dito pelo louco era ouvido como um saber importante e necessário, capaz até de modificar os acontecimentos, de interferir no destino dos homens. Acreditava-se que as frases enigmáticas (na realidade incompreensíveis) dos loucos aproximavam os homens das ordens dos deuses mitológicos do Olimpo. A loucura encontrou, então, nesse período, espaço para exprimir-se, não sendo necessário controlá-la ou excluí-la, pois ela era transformada pela cultura em um

(1) TEXTOS de apoio em saúde mental. Rio de Janeiro: Escola Politécnica de Saúde Joaquim Venâncio, 2003.p. 13. 
instrumento necessário para que se compreendessem as mensagens divinas e se lidasse com os limites do conhecimento."

No mesmo diapasão, Augusto César de Farias Costa, médico-psiquiatra e coordenador do Programa de Saúde Mental NESP/CEAM/UNB(2):

"Dessa maneira, as sociedades ditas mais primitivas consideravam os indivíduos que apresentavam transtornos mentais como emissários da divinidade e assim portadores de poderes sobrenaturais. A inserção da sua diferença numa perspectiva religiosa proporcionava ao louco um lugar contextualizado dentro da comunidade, fazendo com que a sua singularidade, ao invés de ser excluída, fosse assimilada como uma contribuição e não como um subtração ao bem-estar comum. Assim, já na antiga Mesopotâmia, no Egito Antigo, entre os hebreus e os persas e até no extremo Oriente, a loucura era entendida como uma condição especial que conferia ao indivíduo que a apresentasse uma feição próxima ao divino."

Foi, entrementes, na ldade Média (séculos $V$ a XV) que o preconceito contra os loucos se alastrou, sendo certo que tal período é considerado pelos estudiosos da saúde mental como o "marco referencial da mudança de postura para com os acometidos por transtornos psíquicos".

O culto Michel Foucault dedicou parte de sua extensa obra "A História da Loucura" à análise da intolerância medieval européia para com a frágil coletividade dos acometidos por transtornos psíquicos, que chegou a ser perseguida, à época, pelo Tribunal da Santa Inquisição.

Com o advento da chamada "Era da Razão" (séculos XVII e XVIII), e do lançamento da paradigmática obra de René Descartes, "Discurso sobre o Método", de 1637, lançaram-se as bases do moderno Racionalismo, fornecendo a tônica para a compreensão do mundo sem as interferências determinantes da tradição e da fé medievais.

Assim, muitos dos dogmas difundidos na Europa medieval foram revistos, sendo certo que, no final do século XVIII o médico sanitarista francês Philippe Pinel, incumbido pela Assembléia Francesa de realizar um ordenamento em dois locais onde se "misturavam excluídos de todo tipo" (Bicêtre e Sapêtrière), lançou as bases inaugurais da medicina mental, também conhecida como psiquiatria.

Surgem aqui duas idéias fundamentais para a compreensão dos fenômenos relativos à saúde mental: 1) a loucura como doença a ser tratada com o ocultamento e a exclusão com vistas a uma "cura"; e 2) a figura do hospital psiquiátrico (hospício ou manicômio) como o lugar social dos loucos.

(2) COSTA, Augusto César Farias. Saúde mental e reforma psiquiátrica. In: COSTA, Augusto César Farias. Direito sanitário e saúde pública. Brasília: Síntese, 2003, v. 1.p. 144. 
Tal visão perdurou ao longo do século XIX, estando os métodos médico-psiquiátricos empregados no Brasil em plena consonância com o modelo europeu de tratamento dos acometidos por transtornos psíquicos.

Nesse contexto, merece aqui referência a paradigmática obra "O Alienista" do magistral Machado de Assis, homem da época, que com a perspicácia e a genialidade peculiares, conseguiu lançar uma visão crítica sobre o tema, reafirmando a idéia de que a fronteira entre a suposta sanidade e a loucura é, em realidade, bastante tênue e criticando a visão confinadora do hospital psiquiátrico.

No conhecido conto o "Bruxo do Cosme Velho" lançou severa crítica ao manicômio (na obra, o local era denominado "Casa Verde"), onde o médico psiquiatra Dr. Simão Bacamarte, "filho da nobreza da terra e o maior dos médicos do Brasil, de Portugal e das Espanhas", visando descobrir a cura para a loucura, enclausurou a quase totalidade da população da cidade fluminense de Itaguaí por acreditar que todos estavam acometidos por ela. Ao final, o protagonista liberta todos os internos e interna a si próprio, ao concluir ser ele o único louco entre os convivas.

Com os avanços trazidos pela Psicanálise (Freud) e novos modelos psiquiátricos, ao longo do século XX muitas críticas foram lançadas ao modelo pineliano, apregoando a superação do modelo hospitalar.

O modelo assistencial/asilar passou a ser considerado desumano, sugerindo os especialistas a criação de novos espaços fora dos limites das cidades onde o internado dispusesse de melhores condições de habitabilidade e a introdução de concepções que pudessem trazer maior clareza sobre a natureza humana do louco e de sua subjetividade.

Os estudiosos chegaram à conclusão de que o modelo assistencial (hospitalar/asilar) era inadequado, sendo considerado violento, desumano, ineficaz e iatrogênico, tratando-se, destarte, de um modelo esgotado.

Não nos parece afinal, coerente apregoar a reabilitação e inserção social das pessoas acometidas por transtornos psíquicos retirando-as pura e simplesmente do convívio social.

Citando, mais uma vez, o renomado psiquiatra Augusto Cesar de Farias Costa $^{(3)}$, é de se notar que:

"As razões desse esgotamento já são por demais conhecidas. Contudo, vale lembrar que por ser asilar, manicomial, institucionalizador, violento, desumano, ineficaz, iatrogênico e caracterizado por uma prática assistencial balizada no silenciamento dos sintomas e na repressão da subjetividade esse modelo não merece mais nenhuma chance."

(3) COSTA, Augusto César Farias. Saúde mental e reforma psiquiátrica. In: COSTA, Augusto César Farias. Direito sanitário e saúde pública. Brasília: Síntese, 2003, v. 1.p. 157. 
A superação do modelo assistencial no Brasil culminou com a denominada reforma psiquiátrica que tem como objetivo primordial acabar com a cultura manicomial e buscar a recontextualização dos acometidos de transtornos mentais por meio do asseguramento de seus direitos e suas cidadanias.

Não se quer com isso, pura e simplesmente, abolir a figura do hospital psiquiátrico e, sem qualquer cautela, "libertar" pessoas que foram enclausuradas (muitas vezes de forma equivocada) durante longos períodos.

Quer-se apenas combater uma cultura de internação como único modo de tratamento da doença mental e enxergar em mecanismos alternativos, testados na prática no Brasil e no mundo, soluçōes mais humanas para a problemática apresentada.

Como bem registra a psicóloga Jacyara C. Rochael Nasciutti(4):

"O Ministério da Saúde e o Legislativo, por sua vez, se comprometem com o movimento e estabelecem regras e normas que implicam na reestruturação ou na elaboração de novos modelos assistenciais que contemplem a criação de dispositivos terapêuticos e mudanças nos atendimentos prestados à clientela e que se apóiam numa nova concepção do "lugar psicossocial" do cliente portador de "sofrimento psíquico grave", principalmente no que concerne aos aspectos de reconhecimento da cidadania, reinserção social e familiar e descronificação para os já inseridos no modelo vigente (pacientes asilares) e de formas de atendimento que evitem a internação e conseqüente cronificação dos pacientes ambulatoriais. Em ambos os casos deve prevalecer o princípio da não exclusão e do respeito à pessoa humana."

O chamado "Movimento Antimanicomial", nos últimos anos, ganhou status de verdadeiro movimento social, abrangendo a prática de atos públicos, realização de Congressos na área da Saúde Mental, criação de Organizaçōes Não-Governamentais, efetivação de estudos interdisciplinares sobre a problemática assistencialista/asilar etc.

A Sociologia, o Serviço Social, a Psicologia, a Psiquiatria e o Direito, dentre outras relevantes disciplinas, vêm trabalhando a idéia de superação do modelo asilar e atribuindo maior importância às idéias de reinserção social da pessoa acometida por transtorno psíquico.

Outrossim, no campo das artes não foram poucos os artistas que se dedicaram à superação de dogmas na temática da loucura, merecendo aqui citação, apenas a título ilustrativo, de filmes clássicos como "Personna" do grande gênio do cinema, o diretor sueco Ingmar Bergman, e "Um Estranho

(4) NASCIUTTI, Jacyara C. Rochael. A instituição como via de acesso à comunidade. In: CAMPOS, Regina Helena de Freitas (Org). Psicologia social comunitária. da solidariedade à autonomia. 9. ed. Rio de Janeiro: Vozes, 2004. p. 119-120. 
no Ninho" do ilustrado diretor tcheco Milos Forman (este, aliás, abordando de forma direta a indignidade do tratamento manicomial).

No Brasil, o cinema também não se fez de rogado e enfrentou de forma brilhante a problemática asilar em um recente filme de qualidade indubitável: "Bicho de Sete Cabeças", da diretora Lais Bodanzky. Na consagrada película, apresenta-se a história verídica de um rapaz usuário do entorpecente vulgarmente conhecido como "maconha", internado, de forma arbitrária, como louco. Trata-se de uma verdadeira "odisséia ao inferno manicomial brasileiro".

Como se vê, a causa antimanicomial vem ganhando repercussão nos últimos anos, eis que transborda a questão meramente pessoal ou familiar e ganha contornos de problema social, merecendo por parte do Estado uma resposta adequada na condução de políticas públicas na área da saúde mental.

\section{AS PESSOAS ACOMETIDAS POR TRANSTORNOS PSÍQUICOS COMO SUJEITOS DE DIREITOS E COMO COLETIVIDADE EM SITUAÇÃO DE OPRESSÃO: DO DIREITO Aे DIFERENÇA COMO GARANTIA DE DIGNIDADE HUMANA E ISONOMIA DOS QUE PADECEM DE PROBLEMAS DE SAÚDE MENTAL}

Como visto, a opção estatal de confinamento das pessoas acometidas por transtornos psíquicos se justificou, ao longo da história, pelo suporte teórico que a própria medicina psiquiátrica the propiciava.

A superação do modelo psiquiátrico tradicional/asilar, entretanto, surgiu de setores da própria medicina que passaram a enxergar nos acometidos por transtornos psíquicos pessoas humanas e, portanto, sujeitos de direitos e titulares de cidadania.

Constatou-se, então, a necessidade de se reformar toda a estrutura em que se baseava a dogmática psiquiátrica até então em vigor, merecendo citação, a bem sucedida experiência italiana de Basaglia (Movimento Democrático pela Reforma Psiquiátrica).

Nesse contexto, assevera com autoridade o estudioso do tema Manuel Desviat $^{(5)}$ :

"As críticas à eficácia do asilo não tardaram a se produzir, mas foi depois da Segunda Guerra Mundial, em tempos de crescimento econômico e reconstrução social, de grande desenvolvimento dos movi-

(5) DESVIAT, Manuel. A reforma psiquiátrica. 1. ed. Rio de Janeiro: Fiocruz, 1999. p. 23. 
mentos civis e de maior tolerância e sensibilidade para com as diferenças, que a comunidade profissional e cultural, por vias diferentes, chegou à conclusão de que o hospital psiquiátrico deveria ser transformado ou abolido. O New Dea/norte-americano e a revolta contra as instituiçōes, que atingiu seu ponto máximo no questionamento sem precedentes da ordem social contemporânea do maio francês de 1968, influíram decisivamente na ruptura do paradigma psiquiátrico construído ao longo do século XIX, do consenso Kraepeliniano de que falamos em outro texto e que requer um curso irreversível da doença e do manicômio. Junto com essa vontade coletiva de criar uma sociedade mais livre e igualitária, mais solidária, a descoberta dos medicamentos psicotrópicos e a adoção da psicanálise e da saúde pública nas instituições da psiquiatria foram elementos propulsores dos diferentes movimentos de reforma psiquiátrica, desde a desinstitucionalização norte-americana até a política de setor francesa."

Como pessoas humanas que são os acometidos por transtornos psíquicos e por força de mandamento da Carta Magna que se encontra inserido em seu art. 1ํ, inciso III (Princípio da Dignidade da Pessoa Humana), de caráter fundante da República Federativa do Brasil, a esta coletividade só poderá ser dispensado um tratamento digno.

É claro que, diante das características singularizantes do doente mental, só se poderá fornecer respostas adequadas às suas reais necessidades/ limitaçōes, se forem observadas especificidades relativas à individualidade da pessoa humana acometida por transtorno psíquico. Só assim se estará dispensando um autêntico tratamento digno nos moldes prescritos pela Constituição Cidadã.

É nesse contexto que a doutrina mais atualizada vem defendendo a idéia do assim denominado direito à diferença.

A exemplo do que ocorre com outras coletividades que vivem em estado de opressão, a noção de respeito à diferença está intimamente ligada à própria idéia de dignidade humana das pessoas que as compōem.

Significa dizer que nas sociedades modernas só se pode implementar a verdadeira Democracia quando se respeita a diferença dos elementos humanos que lhe integram. Em outras palavras, só há democracia onde existe Pluralismo.

Nesse sentido, um Estado Democrático e Constitucional de Direito, como é o Brasil, deve, necessariamente, ser pluralista e inclusivo, como bem registra, em obra referencial, o ilustre Procurador da República Álvaro Ricardo de Souza Cruz'(6):

(6) CRUZ, Álvaro Ricardo de Souza. O direito à diferença. 3. ed. Belo Horizonte: Del Rey, 2001. p. 127. 
"O paradigma do Estado Democrático de Direito não apenas incorporou no rol de direitos fundamentais novas relações jurídicas, como aquelas atinentes aos direitos difusos, mas também renovou a concepção de outros tantos. Assim, a semiótica jurídica do direito à igualdade, ampliando seu campo de incidência e sua plurissignificação, é indispensável sob a ótica da dignidade humana.

Uma sociedade calcada nestes princípios é necessariamente pluralista e inclusiva, pois deve garantir/estimular a participação de todos, aproveitando as diferentes cosmovisōes e experiências humanas, reconhecendo/desenvolvendo o potencial de cada cidadão.

Esta sociedade deve trabalhar no sentido de oferecer oportunidades para que cada cidadão possa ser respeitado, garantindo-lhe mecanismos para que a mesma consiga a integridade de sua autonomia, autodeterminada e participativa."

Pode-se, assim, constatar que a concepção pluralista do Estado engloba múltiplas facetas que sempre rechaçam o autoritarismo e valorizam as forças sociais dos grupos coletivos, como bem assinala o grande mestre $\mathrm{J}$. J. Gomes Canotilho(7):

"O pluralismo é uma realidade: sociedade heterogênea de classes e fraçōes de classes, grupos sociais, econômicos, diversidades culturais e ideológicas. Por outro lado, no pluralismo é assinalada uma evidente dimensão ou componente normativa: acentuação do pluralismo de expressão e organização política democráticas como elementos constitutivos de um estado democrático e, nesta medida, recusa de quaisquer reduções autoritárias. Além disso pretende-se reconhecer às forças sociais e aos grupos colectivos capacidade de transformação qualitativa das relaçōes humanas."

Por sua vez, podemos constatar que o Princípio da Igualdade (Princípio Isonômico) foi inserido como direito fundamental (art. 5º, caput) em nosso sistema constitucional. Goza, outrossim, do status de direito humano, não há dúvidas.

Com o postulado da isonomia quer-se transmitir não apenas a noção de uma igualdade formal (igualdade de fato), mas, também, uma visão complementar e indispensável de igualdade material. Esta pressupõe a constatação das desigualdades fáticas e a heterogeneidade de valores, condiçōes e interesses do componente principal do ambiente social: o Homem.

Por isso, quando se fala em direito à diferença, quer-se referir, em última instância, à própria noção de igualdade, ou seja, de encarar as desigualdades fáticas dos homens como elementos a serem considerados para

(7) CANOTILHO, J. J. Gomes. Direito constitucional e teoria da constituiçăo. 4. ed. Coimbra: Almedina, 2001.p. 1359. 
a implementação da verdadeira isonomia. Não se pode jamais esquecer e atualizar a máxima aristotélica de que "a igualdade consiste em tratar igualmente os iguais e desigualmente os desiguais".

Nesse sentido, o ilustrado professor Marcelo Neves(8) pondera com a propriedade que the é peculiar:

"O princípio da igualdade, entretanto, não se restringe à integração sistêmica igualitária. A noção de integração procedimental igualitária pode ser lida a partir de duas perspectivas diversas e inseparáveis. Do ponto de vista sistêmico, a questão refere-se à neutralização de desigualdades fáticas na consideração jurídica de indivíduos e grupos. Mas, por outro lado, é imprescindível que na esfera pública pluralista tenha-se desenvolvido a idéia de que as diferenças sejam recíprocas e simetricamente respeitadas. Isso exige que os procedimentos constitucionais apresentem-se como sensíveis ao convívio dos diferentes e, dessa maneira, possibilitem-se um tratamento jurídico igualitário. (...) Evidentemente, a "fundamentalidade" do direito de igual respeito e consideração exige uma esfera pública pluralista onde se assente o respeito recíproco e simétrico às diferenças."

Portanto, o confinamento das pessoas acometidas por transtornos psíquicos não condiz com a visão inclusiva que deve ser preservada em uma verdadeira democracia.

O Estado, responsável pelo dito bem comum não pode mais atuar de forma a vulnerar grupos de cidadāos, que pelo fato de estarem acometidos por transtornos psíquicos, são segregados sem observância de critérios razoáveis e sem a dignidade mínima que se exige no trato com a pessoa humana em qualquer situação de vida.

De há muito já alertava o jusfilósofo Miguel Reale ${ }^{(9)}$ :

"Para tanto, torna-se necessário estabelecer um relacionamento equilibrado e dinâmico entre o Poder Público e a sociedade, de tal modo que o Estado não seja fortalecido em si e por si mesmo, isto é, em função dos fins que lhe são próprios, mas sim em razão das finalidades dos indivíduos, dos grupos naturais e da coletividade em seu conjunto. Por outras palavras, as regras de direito devem ter a sociedade civil como sua principal destinatária."

Na mesma esteira de pensamento, Norberto Bobbid(10), analisando o "Estado Representativo", constata a transmutação do papel deste perante a

(8) NEVES, Marcelo. Justiça e diferença numa sociedade global complexa. In:SOUZA, Jessé (Org). Democracia hoje. novos desafios para a teoria democrática contemporânea. 7. ed. Brasília: UNB, 2001. p. 336-337.

(9) REALE, Miguel. Liberdade e democracia. 3. ed. São Paulo: Saraiva, 1987. p. 40.

(10) BOBBIO, Norberto. Estado, governo e sociedade. para uma teoria geral da política. 6. ed. São Paulo: Paz e Terra, 1999. p. 117. 
sociedade civil, apontando o reconhecimento do direitos humanos como marco divisor de dois momentos históricos distintos:

"O reconhecimento dos direitos do homem e do cidadão, primeiro apenas doutrinário através dos jusnaturalistas, depois também prático e político através das primeiras Declarações de direitos, representa a verdadeira revolução copernicana na história da evolução das relaçōes entre governantes e governados: o Estado considerado não mais ex parte principis mas ex parte populi. O indivíduo vem antes do Estado. O indivíduo não é pelo Estado mas o Estado pelo Indivíduo."

Nesse contexto, se o Brasil efetivamente é um Estado de Direito Democrático-Constitucional em que o poder é exercido pelo e para o povo (art. $1^{\circ}$, parágrafo único da $(F)$, e, se dentro deste universo existem grupos humanos em flagrante situação de opressão, a verdadeira democracia só poderia vir a ser implementada com o tratamento digno dispensado a essas coletividades, garantindo-lhes o direito de ser diferente.

Portanto, a desinstitucionalização e a efetiva inserção social de portadores de sofrimento psíquico (aptos a tanto) à comunidade se afiguram como medidas necessárias e de urgência, sob pena de se dar continuidade/chancelar arbitrariedades perpetradas em desfavor desse grupo em situação de vulnerabilidade.

\section{DAS POLÍTICAS PÚBLICAS ESPECÍFICAS DE DESINSTITUCIONALIZAÇÃO E DA ATUAÇÃO DO MINISTÉRIO PÚBLICO PARA SUA IMPLEMENTAÇÃO PELA VIA JUDICIAL}

A Constituição Federal, em seu art. 6º erigiu o direito à saúde como um direito social fundamental.

Além de qualificar-se como um direito fundamental (assim reconhecido pelo Supremo Tribunal Federal em decisão plenária aqui transcrita), o direito à saúde identifica-se como um direito humano, na medida em que é conseqüência lógica e indissociável do próprio direito à vida.

A relevância pública e fundamentalidade do direito à saúde se extraem, também, dos inúmeros tratados internacionais na área de saúde dos quais o Brasil é signatário, sendo o mais importante deles a Constituição da OMS (Organização Mundial da Saúde) que contempla a idéia do direito à saúde como um direito humano e universal.

Prescreve a Lei Maior, em seu art. 196, que:

"A saúde é direito de todos e dever do Estado, garantido mediante políticas sociais e econômicas que visem à redução do risco de doença e de outros 
agravos e ao acesso universal e igualitário às ações e serviços para sua promoção, proteção e recuperação".

As Constituiçōes Estaduais, quase sempre, contemplam dispositivos específicos que garantem aos cidadãos o direito à saúde (e, especificamente, à saúde mental, como, por exemplo, o art. 204 da Lei Orgânica do Distrito Federal, que prevê ser um direito de todos e um dever do Estado a garantia do bem-estar mental dos cidadãos).

No campo da saúde mental, no Brasil vige a importante Lei n. 10.216, de 6 de abril de 2001, que "dispõe sobre a proteção e os direitos das pessoas portadoras de transtornos mentais, redirecionando o modelo assistencial em saúde mental".

O referido diploma legal ficou conhecido, à época de sua edição, como a "lei da reforma psiquiátrica" com sua visão humanizadora do acometido por transtorno psíquico, comprometimento com a visão antimanicomial e com a reabilitação psicossocial do louco.

Trata-se de uma lei nacional, de aplicação direta em qualquer esfera de governo, merecendo suas prescrições obediência de todos os Entes Federados incumbidos de políticas públicas voltadas para a área da saúde mental, nos seguintes termos:

"Art. $3^{2}$ É responsabilidade do Estado o desenvolvimento da política de saúde mental, a assistência e a promoção de açōes de saúde aos portadores de transtornos mentais, com a devida participação da sociedade e da família, a qual será prestada em estabelecimento de saúde mental, assim entendidas as instituiçōes ou unidades que ofereçam assistência em saúde aos portadores de transtornos mentais."

Dispõe o parágrafo único do art. $2^{\circ}$ da "Lei da Reforma Psiquiátrica":

"São direitos da pessoa portadora de transtorno mental:

I - ter acesso ao melhor tratamento do sistema de saúde, consentâneo às suas necessidades;

II - ser tratada com humanidade e respeito e no interesse exclusivo de beneficiar sua saúde, visando alcançar sua recuperação pela inserção na família, no trabalho e na comunidade; (...)

VIII - ser tratada em ambiente pelos meios menos invasivos possíveis;

IX - ser tratada, preferencialmente, em senviços comunitários de saúde mental."

Especificamente, para os pacientes há muito hospitalizados/institucionalizados, prescreveu $o$ art. $5^{\circ}$ da Lei n. 10.216/01 um tratamento diferenciado, objeto de uma política pública específica de desinstitucionalização, determinando que:

"O paciente há longo tempo hospitalizado ou para o qual se caracterize situação de grave dependência institucional, decorrente de seu quadro clínico ou de 
ausência de suporte social, será objeto de política específica de alta planejada reabilitação psicossocial assistida, sob responsabilidade da autoridade sanitária competente e supervisão de instância a ser definida pelo Poder Executivo, assegurada a continuidade do tratamento, quando necessário."

Nesse contexto, pode-se perceber que o legislador acabou por positivar em lei a opção política de implementação das chamadas residências terapêuticas já que, como visto, o órgão máximo de execução da saúde no Brasil, o Ministério da Saúde, ao editar a Portaria n. 106, em 11 de fevereiro de 2000, acabou por introduzir os serviços residenciais terapêuticos no âmbito do Sistema Único de Saúde.

Consagrou-se, nesse momento regulamentar, a opção política do estado de implementar os "lares abrigados" como sendo a "medida de desinstitucionalização" a ser efetivada por determinação do art. 50 da Lei n. 10.216/01.

O Sistema Único de Saúde vem, nos últimos anos, dedicando especial atenção ao desenvolvimento de programas de reinserção social de doentes mentais como o "De Volta para Casa", "De Reestruturação dos Hospitais Psiquiátricos" e, em especial, o serviço residencial terapêutico. Tudo isso com o escopo de resgatar a cidadania e a dignidade das pessoas acometidas por transtornos psíquicos.

Tais processos de reabilitação psicossocial vêm se demonstrando altamente eficazes em inúmeras experiências práticas, seja no Brasil, seja no exterior.

Especificamente, o Serviço Residencial Terapêutico ("SRT", "lares abrigados", ou, simplesmente, "residências terapêuticas"), segundo definição colacionada em material de divulgação elaborado pelo Ministério da Saúde "são casas localizadas no espaço urbano, constituídas para responder às necessidades de moradia de pessoas portadoras de transtornos mentais graves, institucionalizadas ou não".

O parágrafo único do art. $1^{\circ}$ da Portaria n. 106/00 elucida que "Entende-se por Serviços Residenciais Terapêuticos, moradias ou casas inseridas, preferencialmente, na comunidade, destinadas a cuidar dos portadores de transtornos mentais, egressos de internaçōes psiquiátricas de longa permanência, que não possuam suporte social e laços familiares e, que viabilizem sua inserção social".

Como se vê, os Lares Abrigados são uma experiência pragmática de reinserção da pessoa acometida por um transtorno psíquico institucionalizada e, no mais das vezes, rejeitadas pela própria família.

Para os pesquisadores da Escola Politécnica de Saúde Joaquim Venânciod(11):

(11) TEXTOS de apoio em saúde mental. cit., p. 44. 
"Os Lares Abrigados, ou Serviços Residenciais Terapêuticos, vêm ao encontro da necessidade dos usuários de terem a sua própria casa. Muitos usuários perderam contato com a família após anos de internação, ou não têm condiçōes de morar com os parentes e acabavam ficando internados nos hospitais psiquiátricos por não terem para onde ir (as chamadas "internaçōes sociais"). Os Lares Abrigados permitem que essas pessoas tenham o seu espaço, com suas roupas e objetos pessoais, uma conquista aparentemente simples, mas fundamental no processo de resgate da cidadania dessa população."

Desde o início da década de 90 , inúmeras foram as experiências práticas de implantação das residências terapêuticas no Brasil (em especial, nos estados da Bahia, Sergipe, São Paulo, Rio de Janeiro e Rio Grande do Sul), sendo certo que o sucesso dessas empreitadas geraram subsídios para a elaboração da Portaria n. 106/00 do Ministério da Saúde, que introduziu os "lares abrigados" no âmbito do SUS.

Atualmente, existem 256 SRTs em quatorze estados e 45 municípios do país, onde moram 1.400 pessoas.

Estimativas recentes da Coordenação Geral de Saúde Mental, do Ministério da Saúde, apontam a existência de, aproximadamente, 12 mil pacientes internados que poderiam ser beneficiados pelos lares abrigados.

Tais dados evidenciam a necessidade de significativa expansão do número de residências terapêuticas, de modo a reduzir a segregação e aumentar a reinserção social dos pacientes doentes mentais.

Com o claro intuito de "estimular" a implantação das residências terapêuticas nos entes federados, o Ministério da Saúde fez publicar a Portaria n. 246, de 17 de fevereiro de 2005, na qual institui a destinação de vultoso incentivo financeiro para implantação dos serviços residenciais terapêuticos, afastando, assim, qualquer discussão acerca das chamadas reservas da cláusula do possível.

O direito à saúde (em sentido amplo) deve ser visto como possuidor de uma natureza público-subjetiva, representando prerrogativa jurídica indisponível assegurada à generalidade das pessoas pela própria Constituição da República.

Tal direito é, portanto, um direito subjetivo público e indisponível, que confere a qualquer cidadão a garantia de uma imediata prestação sanitária, se necessário pela via judicial, por iniciativa do próprio titular ou de órgãos com atribuição para a tutela do direito à saúde, como é o caso do Ministério Público.

Traduz, outrossim, a idéia de que o Poder Público, incumbido da formulação e da implementação das políticas públicas que visem a garantir aos cidadãos a prestação de serviços na área de saúde, deve tornar efetivas tais 
prestações, promovendo em favor das pessoas e das comunidades medidas (preventivas e de recuperação) na busca de emprestar verdadeira concretude ao direito à saúde.

Não basta, contudo, que o Estado meramente proclame o reconhecimento formal de um direito à desinstitucionalização (como o fez ao editar a Lei n. 10.216/01 e ao regulamentar a Portaria n. 106/00, integrando os serviços residenciais terapêuticos no âmbito do Sistema Único de Saúde).

Torna-se essencial que, para além da simples declaração legal desse direito, seja ele integralmente respeitado e implementado, especialmente, naqueles casos em que o direito se qualifica como uma verdadeira prerrogativa jurídica da qual decorre o poder do cidadão de exigir do estado a implementação de prestações positivas impostas pelo próprio ordenamento.

Nesse contexto, a doutrina especializada do direito sanitário e a jurisprudência do STF e do STJ entendem que, em se tratando do direito à saúde, as leis devem ser aplicadas de molde a lhes garantir a máxima efetividade, diante da singular importância do direito à saúde (e à vida) na ordem constitucional. Por isso, é que estudiosos do tema afirmam que as normas constitucionais referentes à saúde são de aplicabilidade imediata e eficácia plena.

Nesse sentido, confira-se o pensamento do culto Germano Schwartz ${ }^{(12)}$ :

"Com o reconhecimento normativo, doutrinário e jurisprudencial de que a saúde é direito fundamental do homem, temos que as normas constitucionais referentes à saúde são normas de aplicabilidade imediata e de eficácia plena, caráter este reconhecido pelo órgão máximo do Poder Judiciário Brasileiro - o Supremo Tribunal Federal (STF) -, a quem cabe a guarda precípua da Constituição. Na decisăo do Agravo Regimental em Agravo de Instrumento n. 238.328-0, o Relator Ministro Marco Aurélio afirma que o preceito do art. 196 da Carta da República é de eficácia imediata.

Ademais, o corpo da própria Carta Magna define, no art. $5^{\circ}, \S 1^{\circ}$, que as normas definidoras dos direitos e garantias fundamentais têm aplicação imediata. Tal preceito deve ser analisado conjuntamente com o art. 5, XXXV, da CF/88, que obriga o Poder Judiciário a decidir sobre o caso concreto (inafastabilidade do controle Judiciário) (...)

Por outro lado ângulo, em uma verdadeira hermenêutica voltada aos fins da justiça social, esta discussão acerca da programaticidade ou da aplicabilidade das normas sanitárias seria inócua, afinal qual o sentido de não fazer valer normas que procuram proteger o maior bem que

(12) SCHWARTZ, Germano. Direito à saúde: efetivação em uma perspectiva sistêmica. 3. ed. Porto Alegre: Livraria do Advogado, 2001. p. 63. 
todos possuímos (a vida)? De que valeria o poder constituinte originário autorizar ao poder constituinte instituído que este viesse a prejudicá-lo por interesses que não os seus, negando o caráter comunitário da nossa Lei Maior?"

Não é de hoje que os juristas constataram que, em matéria de direitos fundamentais, a problemática se transferiu da enunciação e fundamentação dos mesmos, para centrar o foco na realização dos direitos proclamados.

Nesse contexto, acentua o grande pensador Norberto Bobbid ${ }^{(13)}$ :

"... o problema que temos diante de nós não é filosófico, mas jurídico e, num sentido amplo, político. Não se trata de saber quais e quantos são esses direitos, qual é a sua natureza e seu fundamento, (...), mas sim qual é o modo mais seguro para garanti-los, para impedir que, apesar das solenes declarações, eles sejam continuamente violados."

No que tange à concretização dos direitos sociais fundamentais, como é o caso do direito à saúde, a doutrina dedicada aos direitos humanos tem enfocado a problemática sob o manto de duas teorias: a da indivisibilidade dos direitos humanos e a da proibição do retrocesso social.

Por indivisibilidade dos direitos humanos restou consagrado que os direitos civis e políticos só se realizam plenamente com o gozo dos direitos sociais, não sendo possível assegurar uns sem a implementação dos outros (idéia de necessária interdependência).

Para o emérito professor Augusto Cançado Trindade ${ }^{(14)}$ a indivisibilidade poderia ser assim visualizada/compreendida:

"Com efeito, a denegação ou violação dos direitos econômicos, sociais e culturais, materializados, e. g., na pobreza extrema afeta os seres humanos em todas as esferas de suas vidas (inclusive a civil e política), revelando assim de modo marcante a inter-relação ou indivisibilidade de seus direitos. A pobreza extrema constitui, em última análise, a negação de todos os direitos humanos. Como falar de direito de livre expressão sem o direito à educação? Como conceber o direito de ir e vir (liberdade de movimento) sem o direito à moradia? Como contemplar o direito de participação na vida pública sem o direito à alimentação? Como referir-se ao direito à assistência judiciária sem ao mesmo tempo ter presente o direito à saúde? $E$ os exemplos se multiplicam. Em definitivo, todos experimentamos a indivisibilidade dos direitos humanos no quotidiano de nossas vidas: é esta uma realidade inescapável. Já não há lugar para as compartimentalizações, impõe-se uma visão integrada de todos os direitos humanos."

(13) BOBBIO, Norberto. A era dos direitos. 5. ed. Rio de Janeiro: Campus, 1992. p. 25.

(14) TRINDADE, Antônio Augusto Cançado. Desenvolvimento económico e intervençáo do Estado na ordem constitucional. estudos em homenagem ao professor Washington Peluso Albino de Souza. Porto Alegre: Sérgio António Fabris, 1997. p. 31. 
Por sua vez, pela teoria da proibição do retrocesso social defende-se a idéia de que os direitos sociais, mesmo diante da sujeição à reserva do possível, uma vez implementados, acabariam por impor uma vinculação da Administração em manter a prestação estatal.

In casu, com a implementação das residências terapêuticas em âmbito nacional e concretização da medida desinstitucionalizadora em inúmeros Entes Federados, resulta a vinculação de qualquer administrador local no sentido de implementar a mesma política pública em seu âmbito, sob pena de ofensa, inclusive, ao Modelo Federativo.

Como já mencionado, o colendo Supremo Tribunal Federal, já se posicionou sobre a questão, reconhecendo a obrigação estatal de implementação de políticas públicas na área de saúde como um direito humano e fundamental e a possibilidade de sua exigibilidade pela via judicial.

Nesse sentido, fixou a Corte Maior que cabe ao Ministério Público e ao Poder Judiciário garantir a implementação das prestações de relevância pública, as ações e serviços de saúde (art. 197 da CF), "naquelas hipóteses em que os órgãos estatais, anomalamente, deixassem de respeitar o mandamento constitucional, frustrando-lhe, arbitrariamente a eficácia jurídicosocial, seja por intolerável omissão, seja por qualquer outra inaceitável modalidade de comportamento governamental desviante".

Em voto paradigmático da lavra do eminente Ministro Celso de Mello, deixou a Suprema Corte assentado que:

"(...) Na realidade, o cumprimento do dever político-constitucional consagrado no art. 196 da Lei Fundamental do Estado, consistente na obrigação de assegurar, a todos a proteção à saúde, representa fator, que, associado a um imperativo de solidariedade social, impõe-se ao Poder Público, qualquer que seja a dimensão institucional em que atue no plano de nossa organização federativa. A impostergabilidade da efetivação desse dever constitucional desautoriza o acolhimento do pleito recursal ora deduzido na presente causa. Tal como pude enfatizar, em decisão por mim proferida no exercício da Presidência do Supremo Tribunal Federal, em contexto assemelhado ao da presente causa (Pet 1.246-SC), entre proteger a inviolabilidade do direito à vida e à saúde, que se qualifica como direito subjetivo inalienável assegurado a todos pela própria Constituição da República (art. 5, caput e art. 196), ou fazer prevalecer, contra essa prerrogativa fundamental, um interesse financeiro e secundário do Estado, entendo uma vez configurado esse dilema - que razōes de ordem ético-jurídica impōem ao julgador uma só e possível opção: aquela que privilegia o respeito indeclinável à vida e à saúde humana, notadamente daqueles, como os ora recorridos, que têm acesso, por força de legislação local, ao programa de distribuição gratuita de medicamentos, instituído em favor de pessoas carentes. (...) 
Cumpre não perder de perspectiva que o direito público subjetivo à saúde representa prerrogativa jurídica indisponível assegurada à generalidade das pessoas pela própria Constituição da República. Traduz bem jurídico constitucionalmente tutelado, por cuja integridade deve velar, de maneira responsável, o Poder Público, a quem incumbe formular - e implementar - políticas sociais e econômicas que visem a garantir aos cidadãos, o acesso universal e igualitário à assistência médico-hospitalar. O caráter programático da regra inscrita no art. 196 da Carta Política - que tem destinatários todos os entes políticos que compõem, no plano institucional, a organização federativa do Estado Brasileiro (José Cretella Junior, "Comentários à Constituição de 1988, Vol. VIII 4332-4334, item n. 181, 1993, Forense Universitária) - não pode converter-se em promessa constitucional inconseqüente, sob pena de o Poder Público, fraudando justas expectativas nele depositadas pela coletividade, substituir, de maneira ilegítima, o cumprimento de seu impostergável dever, por um gesto irresponsável de infidelidade governamental ao que determina a própria Lei Fundamental do Estado. Nesse contexto, incide, sobre o Poder Público, a gravíssima obrigação de tornar efetivas as prestações de saúde, incumbindo-lhe promover, em favor das pessoas e das comunidades, medidas - preventivas e de recuperação - que fundadas em políticas públicas idôneas, tenham por finalidade viabilizar e dar concreção ao direito à saúde - que, representa, no contexto da evolução histórica dos direitos básicos da pessoa humana, uma das expressões mais relevantes das liberdades reais ou concretas - impōe ao Poder Público um dever de prestação positiva que somente se terá por cumprido, pelas instâncias governamentais, quando estas adotarem providências destinadas a promover, em plenitude, a satisfação efetiva da determinação ordenada pelo texto constitucional. Vê-se, desse modo, que, mais do que a simples positivação dos direitos sociais - que traduz estágio necessário ao processo de sua afirmação constitucional e que atua como pressuposto indispensável à sua eficácia jurídica (José Afonso da Silva, "Poder Constituinte e Poder Popular", p. 199, itens n. 20/21, 2000, Malheiros) - , recai sobre o Estado, inafastável vínculo institucional consistente em conferir real efetividade a tais prerrogativas básicas, em ordem a permitir, às pessoas, nos casos de injustificável inadimplemento da obrigação estatal, que tenham elas acesso a um sistema organizado de garantias instrumentalmente vinculado à realização, por parte das entidades governamentais, da tarefa que lhes impôs a própria Constituição. Não basta, portanto, que o Estado meramente proclame o reconhecimento formal de um direito. Torna-se essencial que, para além da simples declaração constitucional desse direito, seja ele integralmente respeitado e plenamente garantido, especialmente naqueles casos em que o direito - como o direito à saúde - se qualifica como prerrogativa jurídica de que decorre o poder do cidadão de 
exigir, do Estado, a implementação de prestações positivas impostas pelo próprio ordenamento constitucional. Cumpre assinalar, finalmente, que a essencialidade do direito à saúde fez com que o legislador constituinte qualificasse, como prestações de relevância pública, as açōes e serviços de saúde (CF, art. 197), em ordem a legitimar a atuação do Ministério Público e do Poder Judiciário naquelas hipóteses em que os órgãos estatais, anomalamente, deixassem de respeitar o mandamento constitucional, frustrando-lhe, arbitrariamente a eficácia jurídico-social, seja por intolerável omissão, seja por qualquer outra inaceitável modalidade de comportamento governamental desviante." (RE n. 267.612-RS, Relator: Ministro Celso de Mello, publicada no DJU de 23.8.2000)

Diante da recalcitrância de alguns entes federados em implementar as residências terapêuticas no âmbito do SUS local (e, note-se, mesmo com o incentivo vindo dos cofres federais), não se vislumbra razão para que o órgão ministerial se esquive de buscar a intervenção judicial, para que se veja implementar, na prática, o direito à saúde (mental) constitucionalmente previsto.

E note-se que a viabilidade do pleito condenatório em obrigação de fazer in casu é plenamente admitida pela jurisprudência dominante do Superior Tribunal de Justiça que firmou a legitimidade do Ministério Público para a propositura de açōes civis púbicas em que se exija a implementação de políticas públicas específicas, quando já regulamentadas em ato administrativo pelo Poder Executivo.

Nesse contexto, merecem transcrição dois esclarecedores arestos daquela Corte Superior:

"ADMINISTRATIVO E PROCESSO CIVIL - AÇÃO CIVIL PÚBLICA - ATO ADMINISTRATIVO DISCRICIONÁRIO: NONA VISÃO.

1. $\mathrm{Na}$ atualidade, $\mathrm{O}$ império da lei e o seu controle, a cargo do Judiciário, autoriza que se examinem, inclusive, as razões de conveniência e oportunidade do administrador.

2. Legitimidade do Ministério Público para exigir do Município a execução de política específica, a qual se tornou obrigatória por meio de resolução do Conselho Municipal dos Direitos da Criança e do Adolescente.

3. Tutela específica para que seja incluída verba no próximo orçamento, a fim de atender a propostas políticas certas e determinadas.

4. Recurso especial provido." (REsp n. 493811/SP, Relatora Ministra Eliana Calmon, Segunda Turma, julgamento em 11.11.03).

"PROCESSUAL CIVIL E ADMINISTRATIVO. COLETA DE LIXO. SERVIÇO ESSENCIAL. PRESTAÇÃO DESCONTINUADA. PREJUÍZO À SAÚDE PÚBLICA. DIREITO FUNDAMENTAL. NORMA DE NATUREZA PROGRAMÁTICA. AUTO-EXECUTORIEDADE. PROTEÇÃO POR VIA DA AÇÃO 
CIVIL PÚBLICA. POSSIBILIDADE. ESFERA DE DISCRICIONARIEDADE DO ADMINISTRADOR. INGERÊNCIA DO PODER JUDICIÁRIO.

1. Resta estreme de dúvidas que a coleta de lixo constitui serviço essencial, imprescindivel à manutenção da saúde pública, o que o torna submisso à regra da continuidade. Sua interrupção, ou ainda, a sua prestação de forma descontinuada, extrapola os limites da legalidade $\theta$ afronta a cláusula pétrea de respeito à dignidade humana, porquanto o cidadão necessita utilizar-se desse serviço público, indispensável à sua vida em comunidade.

2. Releva notar que uma Constituição Federal é fruto da vontade política nacional, erigida mediante consulta das expectativas $\theta$ das possibilidades do que se vai consagrar, por isso cogentes e eficazes suas promessas, sob pena de restarem vãs e frias enquanto letras mortas no papel. Ressoa inconcebível que direitos consagrados em normas menores como Circulares, Portarias, Medidas Provisórias, Leis Ordinárias tenham eficácia imediata e os direitos consagrados constitucionalmente, inspirados nos mais altos valores éticos e morais da nação sejam relegados a segundo plano. Trata-se de direito com normatividade mais do que suficiente, porquanto se define pelo dever, indicando o sujeito passivo, in casu, o Estado.

3. Em função do princípio da inafastabilidade consagrado constitucionalmente, a todo direito corresponde uma ação que o assegura, sendo certo que todos os cidadãos residentes em Cambuquira encartam-se na esfera desse direito, por isso a homogeneidade e transindividualidade do mesmo a ensejar a bem manejada ação civil.

4. A determinação judicial desse dever pelo Estado, não encerra suposta ingerência do judiciário na esfera da administração. Deveras, não há discricionariedade do administrador frente aos direitos consagrados, quiçá constitucionalmente. Nesse campo a atividade é vinculada sem admissão de qualquer exegese que vise afastar a garantia pétrea.

5. Um país cujo preâmbulo constitucional promete a disseminação das desigualdades e a proteção à dignidade humana, alçadas ao mesmo patamar da defesa da Federação e da República, não pode relegar a saúde pública a um plano diverso daquele que o coloca, como uma das mais belas e justas garantias constitucionais.

6. Afastada a tese descabida da discricionariedade, a única dúvida que se poderia suscitar resvalaria na natureza da norma ora sob enfoque, se programática ou definidora de direitos.

7. As meras diretrizes traçadas pelas políticas públicas não são ainda direitos senão promessas de lege ferenda, encartando-se na esfera insindicável pelo Poder Judiciário, qual a da oportunidade de sua implementação.

8. Diversa é a hipótese segundo a qual a Constituição Federal consagra um direito e a norma infraconstitucional o explicita, impondo-se ao judiciário torná-lo realidade, ainda que para isso, resulte obrigação de fazer, com repercussão na esfera orçamentária.

9. Ressoa evidente que toda imposição jurisdicional à Fazenda Pública implica em dispêndio e atuar, sem que isso infrinja a harmonia dos poderes, porquanto 
no regime democrático e no estado de direito o Estado soberano submete-se à própria justiça que instituiu. Afastada, assim, a ingerência entre os poderes, o judiciário, alegado o malferimento da lei, nada mais fez do que cumpri-la ao determinar a realização prática da promessa constitucional." (REsp n. 575.998, Relator Ministro Luiz Fux, 1 Turma STJ, data do julgamento: 7.10.04).

A jurisprudência só consagrou o pensamento que já vinha, de há muito, se desenvolvendo em seio doutrinário por autores da envergadura de Rodolfo de Camargo Mancuso(15), que defendendo o uso da ação civil pública como instrumento de controle judicial das chamadas políticas públicas, assevera:

"Todo esse contexto vai evidenciando que não há como sustentar o argumento de que a sindicibilidade judicial sobre as políticas públicas implicaria ingerência indevida do Judiciário, assim atritando a separação entre os Poderes. Mutatis mutandis, é o que se colhe do que vem afirmado por Cândido Rangel Dinamarco, ao rebater os argumentos que se levantam contra a eficácia vinculante das súmulas: "Soa cínico ou ao menos ingênuo o discurso voltado a impugnar a legitimidade política dos membros do Poder Judiciário para emitir normas jurídicas com algum caráter de generalidade e abstração"; adiante, conclui: "A proposta de generalizar em alguma medida essa eficácia transcendente está na linha dessas realidades da ordem jurídica e políticoinstitucional do país e nada tem de aberrante sequer no tocante ao dogma da separação dos Poderes." (...)

Todo esse contexto vem, naturalmente, permeado de vontade política, de determinação para atuar, de disposição para fazer operar um efetivo Estado Social de Direito, esperando-se dos operadores do Direito que não se contentem com a fria subsunção dos fatos à norma, mas que dêem um passo a mais, entrando a indagar acerca da idoneidade dos meios empregados para a consecução dos fins e programas estabelecidos na norma de regência; porque é essa - a eficiência na implementação do previstos na normas-objetivo - a atual condição legitimante do Estado moderno."

Abordando a problemática, sob a ótica da fundamentalidade do direito à saúde, a doutrinadora leda Tatiana Cury/16) não vê obstáculos à exigibilidade de prestaçōes materiais através da implementação de políticas públicas/ sociais por parte do Estado, nos seguintes termos:

"A partir dessa interpretação dos direitos humanos, pode-se falar em direitos fundamentais sociais, quais sejam, aqueles que, em vez de

(15) MANCUSO, Rodolfo de Camargo. A ação civil pública como instrumento de controle judicial das chamadas políticas públicas. In: MILARÉ, Edis. Ação civil pública: 15 anos. 2. ed. São Paulo: Revista dos Tribunais, 2002. p. 789-790.

(16) CURY, leda Tatiana. Direito fundamental à saúde. evolução, normatização e efetividade. 2. ed. Rio de Janeiro: Lumen Juris, 2005. p. 3. 
serem direitos contra o Estado, constituem direitos através do Estado, exigindo do Poder Público certas prestações materiais, através da implementação de políticas sociais que facultem o gozo efetivo dos direitos constitucionalmente protegidos."

Considerando que o legislador ordinário nacional (Lei n. 10.216/01) determinou a aplicação de uma política específica de desinstitucionalização e que o Poder Executivo Federal efetivou a opção política de implementar os lares abrigados, no âmbito do Sistema Único de Saúde, por meio da Portaria n. 106/00, surge para qualquer dos entes federados a obrigação de implementá-la, sob pena de incorrer em grave omissão em detrimento de toda uma coletividade e em afronta aos princípios constitucionais do respeito às diferenças (igualdade material), e da dignidade da pessoa humana.

Nessa esteira de pensamento, não se enxerga no ato de implementar as residências terapêuticas no Distrito Federal como ato administrativo discricionário, o que não afastaria, de qualquer sorte, a atuação ministerial para sua implementação, nos termos da consagrada jurisprudência do STJ supratranscrita.

Enxergamos, em realidade, um ato vinculado, não cabendo ao administrador local tecer considerações de conveniência e oportunidade acerca da implementação da política pública específica, haja vista que os requisitos para a prática do ato administrativo já estão preenchidos por disposições de ordem legal e administrativa (Portaria).

Por isso, é arbitrária a não implementação da política pública arquitetada para humanizar o tratamento asilar no âmbito local, ferindo direitos humanos fundamentais de toda uma coletividade, e, em última análise, de toda a sociedade.

O Ministério Público, enquanto órgão representativo dos interesses maiores da sociedade, não pode se abster da defesa de tais direitos, enfrentando a questão em Juízo sempre que se fizer necessário. É óbvio que a via conciliatória, extraprocessual deve ser exaurida para que, só então, se ingresse com uma ação judicial.

Ocorre que o que se constata, na prática, é o completo descomprometimento dos poderes constituídos com a causa sanitária em geral e, em especial, com as questões relativas à saúde mental, o que acaba gerando a opressão de grupos em flagrante situação de vulnerabilidade.

Nesse sentido, os membros do Ministério Público de todo o país, em especial os que atuam nas Promotorias da Saúde, devem se imbuir do seu verdadeiro papel social: o de Promotores da Qualidade de Vida da População. $E$ isso implica, necessariamente, abordar as questões relativas ao direito material à saúde como, por exemplo, aqueles relativos à saúde do idoso, dependência química, saúde do preso, saúde mental, dentre tantos outros. 
A legislação constitucional e infraconstitucional (em especial a Lei Complementar $\mathrm{n}$. 75) dão suporte legal bastante para que o Ministério Público assuma o papel que a sociedade dele espera, cumprindo os desideratos constitucionais de busca da isonomia e da dignidade das pessoas humanas deste país.

A jurisprudência do Supremo Tribunal Federal já se assentou no sentido de que o Ministério Público goza de legitimidade ativa processual para a defesa do direito à saúde e da implementação de políticas públicas na área sanitária, merecendo aqui transcrever, mais uma vez, trecho da lição extraída do voto do eminente Ministro Celso de Mello:

"Cumpre assinalar, finalmente, que a essencialidade do direito à saúde fez com que o legislador constituinte qualificasse, como prestações de relevância pública, as ações e serviços de saúde (CF, art. 197), em ordem a legitimar a atuação do Ministério Público e do Poder Judiciário naquelas hipóteses em que os órgãos estatais, anomalamente, deixassem de respeitar o mandamento constitucional, frustrando-lhe, arbitrariamente a eficácia jurídico-social, seja por intolerável omissão, seja por qualquer outra inaceitável modalidade de comportamento governamental desviante." (RE n. 267.612-RS, Relator: Ministro Celso de Mello, publicada no DJU de 23.8.2000)

Afinal, como bem acentua Cláudio Barros Silva(17):

"A busca da efetivação dos direitos sociais, pela via processual ou extraprocessual, deve levar o Ministério Público à realização do acesso aos direitos fundamentais às milhões de pessoas que vivem à margem do direito. O caminho do Ministério Público, como Instituição da sociedade, deve ser, também, o de efetivação da saúde pública."

A via judicial é extrema, não há dúvidas. Deve-se, sempre buscar a via extraprocessual, conciliatória, do entendimento, em especial, com o Poder Executivo.

Entrementes, inviabilizado tal caminho deve o Ministério Público "assumir a causa" e ingressar em Juízo, utilizando-se dos instrumentos jurídicos consagrados pelo ordenamento jurídico positivo e ratificados pela doutrina e pela jurisprudência nacionais, conforme exposto.

Só assim é que se poderá ver no órgão ministerial uma instituição verdadeiramente legitimada por aqueles a quem tem o dever de servir: o POVO.

(17) SILVA, Cláudio Barros. Seguridade social, controle social e Ministério Público. Revista de Direito, Santa Cruz do Sul, n. 3, p. 109, jul. 1995. 


\section{REFERENCIAS}

BOBBIO, Norberto. A era dos direitos. 5. ed. Rio de Janeiro: Campus, 1992. . Estado, governo e sociedade: para uma teoria geral da política. 6. ed. São Paulo: Paz e Terra, 1999.

CANOTILHO, J. J. Gomes. Direito constitucional e teoria da constituição. 4. ed. Coimbra: Almedina, 2001.

COSTA, Augusto César Farias. Saúde mental e reforma psiquiátrica. In: COSTA, Augusto César Farias. Direito sanitário e saúde pública. Brasília: Síntese, 2003 , v. 1.

CRUZ, Álvaro Ricardo de Souza. O direito à diferença. 3. ed. Belo Horizonte: Del Rey, 2001.

CURY, leda Tatiana. Direito fundamental à saúde: evolução, normatização e efetividade. 2. ed. Rio de Janeiro: Lumen Juris, 2005.

DESVIAT, Manuel. A reforma psiquiátrica. 1. ed. Rio de Janeiro: Fiocruz, 1999.

MANCUSO, Rodolfo de Camargo. A ação civil pública como instrumento de controle judicial das chamadas políticas públicas. In: MILARÉ, Edis. Ação civil pública: 15 anos. 2. ed. São Paulo: Revista dos Tribunais, 2002.

NASCIUTTI, Jacyara C. Rochael. A instituição como via de acesso à comunidade. In: CAMPOS, Regina Helena de Freitas (Org). Psicologia social comunitária: da solidariedade à autonomia. 9. ed. Rio de Janeiro: Vozes, 2004.

NEVES, Marcelo. Justiça e diferença numa sociedade global complexa. In: SOUZA, Jessé (Org). Democracia hoje: novos desafios para a teoria democrática contemporânea. 7. ed. Brasília: UNB, 2001.

REALE, Miguel. Liberdade e democracia. 3. ed. São Paulo: Saraiva, 1987.

SCHWARTZ, Germano. Direito à saúde: efetivação em uma perspectiva sistêmica. 3. ed. Porto Alegre: Livraria do Advogado, 2001.

SILVA, Cláudio Barros. Seguridade social, controle social e Ministério Público. Revista de Direito, Santa Cruz do Sul, n. 3, jul. 1995.

TEXTOS de Apoio em Saúde Mental. Rio de Janeiro: Escola Politécnica de Saúde Joaquim Venâncio, 2003.

TRINDADE, Antônio Augusto Cançado. Desenvolvimento econômico e intervenção do Estado na ordem constitucionat. estudos em homenagem ao professor Washington Peluso Albino de Souza. Porto Alegre: Sérgio Antônio Fabris, 1997. 